\title{
Женское влияние в позднеантичном обществе по данным Аммиана Марцеллина
}

\author{
Анохина Е.B., Семичева Е.A. \\ Белгородский государственный национальный исследовательский университет, \\ 308015, г. Белгород, ул. Победы, 85, \\ E-mail: anokhina-elizavetav@yandex.ru, semicheva@bsu.edu.ru
}

\begin{abstract}
Аннотация. Данная работа посвящена анализу основных форм женского влияния, представленных в тексте «Res Gestae» Аммиана Марцеллина. Исторические сведения, приводимые античным историком в сочетании с данными им оценками, позволяют проиллюстрировать как позитивную, так и негативную модели взаимодействия женщин с мужчинами, наделенными политической властью. Выделены основные типы влияния, оказываемого женщинами на представителей мужского пола в соответствии с установленными инструментами такого влияния - эмоциональным воздействием, семейными связями и денежными ресурсами. Авторы приходят к выводу, что спектр оценок женского влияния, представленный Аммианом Марцеллином, достаточно широк и ситуативен и при этом коррелирует с гендерными представлениями и личными симпатиями автора, а также исповедуемыми им моральными принципами и морализаторским характером работы в целом.
\end{abstract}

Ключевые слова: гендер, феминность, влияние, Поздняя античность, Аммиан Марцеллин.

Для цитирования: Анохина Е.В., Семичева Е.А. 2021. Женское влияние в позднеантичном обществе по данным Аммиана Марцеллина. Via in tempore. История. Политология, 48 (2): 290-298. DOI: $10.52575 / 2687-0967-2021-48-2-290-298$.

\section{Female influence in Late Antique society according to Ammianus Marcellinus}

\author{
Elizaveta V. Anokhina, Elena A. Semicheva \\ Belgorod National Research University, \\ 85, Pobeda St., Belgorod, 308015, Russia \\ E-mail: anokhina-elizavetav@yandex.ru, semicheva@bsu.edu.ru
}

\begin{abstract}
This work is devoted to the analysis of one of the gender problem in the «Res Gestae» by Ammianus Marcellinus, the largest late antique historian of the 2 nd half of the 4th century A. D. Authors of this article concentrate on the main forms of female influence. The historical information and author's assessments give the possibility to illustrate both positive and negative models of interaction between women and men which were endowed with political power. The main types of influence exerted by women on males are highlighted. In accordance with them, the instruments of such influence have been established - emotional impact, relations of marital intimacy, family ties, and patronage and material resources. The authors come to the conclusion that the range of assessments of female influence given by Ammianus Marcellinus is quite wide and situational and correlates with gender perceptions and personal sympathies of the author, as well as his moral principles and the moralizing nature of the work in generally.
\end{abstract}

Key words: gender, femininity, influence, Late Antiquity, Ammianus Marcellinus.

For citation: Anokhina E.V., Semicheva E.A. 2021. Female influence in Late Antique society according to Ammianus Marcellinus. Via in tempore. History and political science, 48 (2): 290-298 (in Russian). DOI: 10.52575/2687-0967-2021-48-2-290-298. 


\section{Введение}

Одним из самых востребованных междисциплинарных подходов в сфере гуманитарного знания в последние десятилетия стал гендерный подход. Очевидно, что это связано с возросшей ролью женщин не только как объектов, но и как субъектов политической жизни обществ Запада, с одной стороны, и с продолжающимся расширением движений феминистской направленности, стремящихся к равноправию полов, с другой стороны. Переосмысление роли женщин в обозначенной сфере ориентирует исследователей на соответствующий анализ исторического материала. Перспективным в этом смысле выглядит период Поздней античности, характеризующийся сложностью социальных и политических связей, а также механизмов различного рода, включая гендерные взаимодействия. Обращение к истории позднего Рима, облик которого во многом определяется идеей континуитета, позволяет рассмотреть основные модели гендерных взаимоотношений в их культурной взаимосвязи с классической античностью. Кроме того, транзитивный характер рассматриваемой эпохи предоставляет возможность проанализировать различные факторы, влияющие на оценку женских поступков обществом, среди которых могут быть как традиционные, так и новые, возникшие под воздействием изменяющейся социальнополитической обстановки.

Одним из наиболее репрезентативных источников по различным аспектам истории IV в. является «Res Gestae» Аммиана Марцеллина. Несмотря на обширную зарубежную и отечественную историографию, посвященную политическим реалиям, представленным в труде выдающегося позднеантичного автора ${ }^{3}$, гендерные аспекты этой проблематики в российском антиковедении остаются недостаточно исследованными. Исключение составляет специально посвященная этому вопросу статья В.А. Дмитриева, в которой автор приходит к выводу о традиционном характере взглядов Марцеллина на женщин и преобладающей негативной их оценке как в соответствии с такой традицией, так и в связи со свойственным ему морализаторством в целом [Дмитриев, 2015]. В зарубежной историографии гендерные вопросы в тексте Аммиана Марцеллина разработаны детальнее [Karau, 1971; Sabbah, 1991; Barnes, 1998; Wieber-Scariot, 1999; Tougher, 2000], однако большинство исследователей все же сосредоточены на характеристиках и оценках тех женщин, которые удостоились внимания античного автора, либо посвящены конкретным персоналиям. Вопросы гендерного взаимодействия и влиятельных эффектов, представленных в «Деяниях», в проблемное поле исследований фактически еще не были включены.

\section{Предмет и методы исследования}

Предметом данной статьи являются не столько сами женщины, сколько специфика их взаимодействия с мужчинами, выражавшегося в различных формах и способах женского влияния, в первую очередь в сфере политики. Обозначенный источник дает возможность выявить механизмы такого влияния, а также оценить отношение Аммиана Марцеллина к подобной роли женщин. Методология работы основана на гендерном подходе, ориентированном на анализ социальный ролей, распределяемых обществом на основании половой принадлежности. Особое значение в применении данного подхода имеют представления о феминности и маскулинности - совокупности психологических характеристик и поведенческих моделей, свойственных женщинам и мужчинам соответственно [Пинчукова, 2017]. В работе применяется сравнительно-исторический метод, позволяющий сопоставить авторские оценки и выявить возможные причины различий в гендерных характеристиках, а также историко-типологический, применение которого обусловлено необходимостью выделения основных типов женского влияния, группировки оценочных суждений и влияющих на них факторов.

${ }^{3}$ Подробнее см.: [Ибатуллин, 2000; Рубцова, 2005; Харченко, 2006; Дмитриев, 2007; Blockley, 1975; Matthews, 1989; Kelly, 2008]. 


\section{Результаты и их обсуждение}

В работе К. Купер, посвященной женским инсинуациям в процессе христианизации римской аристократии, отмечено, что из текстов признанных классиков античной литературы можно выделить две модели традиционно сосуществовавшего женского влияния на мужчин в римском обществе - позитивную и негативную. В рамках позитивной модели воздействие женщины носит умиротворяющий характер, возвращая мужчину на путь спокойствия и рассудительности, а также удерживая его от необдуманных, порой жестоких поступков. В негативной модели, напротив, имеет место провокация со стороны женщин, зачастую руководимых корыстными целями, и даже подстрекательство мужчин к совершению преступных деяний [Cooper, 1992, p. 153]. При этом автор подчеркивает, что для античных авторов принципиально важны самостоятельность мужчин в принятии властных решений и способность противостоять негативному женскому влиянию. Именно поэтому они концентрируют внимание на ситуациях, когда политические лидеры оказывались подвержены воздействию женщин, и это, в свою очередь, оказывалось опасным для общества.

В качестве довольно яркого примера такой модели у Аммиана Марцеллина выступают взаимоотношения цезаря Галла и его жены Константины. Когда Галла принудили «представить подробный отчет о том, на каком основании предал он смерти всех убитых им в Антиохии», он отвечал, что «большинство казней он совершил по наущению жены своей Константины» (Amm. Marc. XIV. 11. 22) [Seyfart, 1978; Кулаковский, Сонни, 1994]. Показательно использование слова «incitante», переводимого как «наущение» или «подстрекательство» [Дворецкий, 1976], которое отражает скрытый характер влияния, оказываемого Константиной на своего супруга.

Античный историк считает, что противостояние женскому влиянию, негативные последствия которого очевидны, было необходимым и являлось признаком соответствующих волевых и моральных качеств мужчины. Именно таким примером позднеантичный автор считает Александра Великого, приводя в качестве антитезы действиям Галла его отказ казнить невиновного по материнской просьбе, несмотря на то, что она пыталась настоять на своем, апеллируя к сыновнему долгу той, которая девять месяцев носила его под сердцем: «Проси, дорогая матушка, другой награды, жизнь человека не искупается никаким благодеянием» (Amm. Marc. XIV. 11. 22).

Более того, реакция Галла вызывает осуждение, поскольку он, с одной стороны, открыто признает зависимость от жены, с другой стороны, пытается тем самым снять с себя часть ответственности. В обоих случаях поведение Галла воспринимается как неподобающее, поэтому Аммиан Марцеллин пишет о гневной реакции Констанция на ответ Галла (Amm. Marc. XIV. 11. 23).

Безусловно, столь категоричные оценки связаны с общим резким неприятием Аммианом Марцеллином личности Галла. Причины этого большинство исследователей видят в принадлежности автора к эллинизированной сирийской знати, которая, как известно, конфликтовала с цезарем [Григорюк, 2009, с. 12; Банников, Шмидт, 2013, с. 91]. Личные мотивы и пристрастия в качестве причины многочисленных обвинений Галла выделяет и И.Е. Ермолова, полагая тем не менее, что историк пытался их преодолеть в своем стремлении к объективности [Ермолова, 2017, с. 246-247]. Таким образом, вероятно, что указание на подверженность негативному женскому влиянию, а главное - прямое признание Галлом этого факта, дополнительно очерняло цезаря в глазах подданных.

Анализируя отношение Аммиана Марцеллина к женщинам, исследователи, как правило, склоняются к мысли о том, что преобладание отрицательных характеристик связывается в первую очередь с несоответствием женского поведения гендерной роли. [Дмитриев, 2015, с. 37]. Действительно, для античного историка женское влияние само по себе не является чем-то предосудительным. Напротив, он полагает прямым предназначением женщины - удерживать мужа от неправильных поступков, однако действовать при 
этом следует в соответствии с феминным статусом: «...ей следовало бы, по свойственной женской природе мягкости, вернуть его полезным советом на путь правды и гуманности...» (Amm. Marc. XIV. 1. 8).

В этой связи приведем фрагмент, в котором Аммиан Марцеллин сообщает о довольно запутанной интриге, затеянной Констанцием для недопущения к императорскому престолу цезаря Галла. Одним из ходов этой интриги было приглашение им в гости своей сестры Константины - жены Галла, которое, по мнению Аммиана Марцеллина, затевалось, чтобы помочь Констанцию избежать подозрений в свой адрес. Историк пишет далее, что Константина, «хотя и колебалась, <..> тем не менее в надежде, что ей удастся смягчить брата, отправилась в путь» (Amm. Marc. XIV. 11. 6).

На наш взгляд, упомянутое намерение «spe tamen quod eum lenire poterit ut germanum profecta» и предпринятое с этой целью рискованное путешествие отражают попытку положительного влияния женщины как на характер облеченного властью мужчины, так и, возможно, на проводимую им политику, тем более что Константина, как уже было отмечено, в изложении античного автора выглядит чрезвычайно деятельной и влиятельной в отношении собственного мужа.

По оценке Аммиана Марцеллина, Констанций в целом был подвержен стороннему воздействию, особенно в вопросах заговоров, мнимых и подлинных: «...вообще был сносный государь, но стоило кому-нибудь, хотя бы и безвестному человеку, шепнуть ему на ухо что-нибудь подобное, как он становился жесток, неумолим и <..> не похож на себя» (Amm. Marc. XIV. 9. 2). Следовательно, излишняя подозрительность, склонность верить слухам и сплетням, даже самым невероятным, и зависимость от мнения приближенных, которые были свойственны императору [Ермолова, 2017, с. 244-245], дают объяснение отмеченному Аммианом Марцеллином стремлению Константины повлиять на брата и, вероятно, сделать шаг к налаживанию отношений между ним и ее супругом. Учитывая также, что в остальных частях своей работы историк рисует Константину как «мегеру в человеческом облике» (Amm. Marc. XIV. 1. 2), оценивая ее поведение и влияние на мужа резко негативно, констатация самой возможности позитивного влияния, смягчения сложной ситуации и проявления вполне феминных качеств является показательной.

Вместе с тем, на наш взгляд, шкала оценки различных способов женского влияния у Аммиана Марцеллина не ограничивается следованием гендерным стереотипам и зависит как от соответствия целей и последствий нормам морали, так и от личных пристрастий автора. Несмотря на общую негативную характеристику Аммианом Марцеллином такого поведения женщин, которое отличалось излишней, по его мнению, активностью, автор превозносит жену Ормизда, находившегося на римской службе перса царского рода, которая «...спасла своего мужа в крайне опасном положении» (Amm. Marc. XXVI. 8. 12). Сама опасность и ее детали в работе не названы, но автор пишет об этой женщине в одобрительном тоне, характеризуя ее поведение как «внушавшее уважение» (Amm. Marc. XXVI. 8. 12). Очевидно, речь идет об идеальном образе римской матроны: добропорядочной жены и матери, неукоснительно соблюдающей предписанные традицией нормы и правила [Шеховцова, 2008, с. 316]. Однако вторая характеристика, позволившая супруге Ормизда достичь цели, звучит как «прославившая ее настойчивость», которая, на наш взгляд, воспринималась римлянами скорее как маскулинная черта. В позднеантичном обществе феминными считались противоположные характеристики - «легкомыслие и непостоянство» (СТ 9. 24. 1). Следовательно, женщине удалось оказать покровительство своему супругу благодаря как женским, так и вполне мужским чертам, проявившимся в ее характере, что не мешает Аммиану Марцеллину одобрительно оценить ее действия.

Показателен также другой случай, связанный с подавлением Феодосием Старшим восстания мавританского царевича Фирма в римской Африке. По свидетельству Аммиана Марцеллина, сестра Фирма предприняла активные действия, позволившие ей с помощью значительных материальных ресурсов сплотить разрозненные племена для поддержки во- 
енной кампании против Рима. Примечательно употребление Аммианом Марцеллином как гендерно окрашенного выражения «женский задор», так и вполне мужского «самым энергичным образом», которые, по мнению автора, в сочетании с «большими богатствами» и позволили женщине реализовать свое влияние: «Progressusque aliquantum iuxta Addense municipium comperit, dissonas cultu et sermonum varietate nationes plurimas unum spirantibus animis, inmanium exordia concitare bellorum, adigente hortanteque maxima spe praemiorum sorore Firmi nomine Cyria, quae abundans divitiis et destinatione feminea, nisibus magnis instituit iuvare germanum» (Amm. Marc. XXIX. 5. 28).

Интересно, что в тексте источника отсутствует прямое осуждение Кирии. Вопервых, возможно, для позднеантичного автора оказался важным мотив помощи брату и отсутствие у женщины собственных корыстных или аморальных целей. Во-вторых, вероятно, сыграло свою роль отношение Аммиана Марцеллина к Феодосию Старшему, которого он стремился прославить в своей работе [Дилигенский, 1961, с. 45]. Масштаб племенного союза, пусть и созданного при непосредственном участии женщины, как и значительность потребовавшихся для его организации усилий и ресурсов, были призваны возвысить победы римского полководца, который его ликвидировал.

Данный фрагмент позволяет, кроме того, выделить в качестве одного из средств женского влияния принадлежавшие женщинам материальные средства. Юридические документы свидетельствуют, что в позднеантичную эпоху владение имуществом в браке повсеместно носило раздельный характер, соответственно, женщина обладала определенной свободой в распоряжении своей долей финансовых ресурсов [Arjava, 1996, p. 143]. Заслуживает внимания замечание Аммиана Марцеллина о том, что вышеупомянутая супруга Ормизды была женщиной «богатой и знатной» (Amm. Marc. XXVI. 8. 12). Стремление к браку с обеспеченной женщиной воспринимается автором одобрительно как способ благородный и безопасный (Amm. Marc. XXVIII. 1. 35).

Источник позволяет утверждать, что, помимо финансовых возможностей и вполне маскулинных настойчивости и энергичности, женщины использовали как средство влияния психологическое воздействие и собственно супружескую близость. В сюжете о знатном нисибийце Краугазии и его жене последняя, попав в персидский плен, сообщает мужу о своем местонахождении. Желая воссоединиться с мужем, она апеллирует к страсти, которую он, по-видимому, испытывал к ней, поскольку, отправив посыльного, распорядилась «передать ему предметы, напоминавшие об их интимной семейной жизни, чтобы Краугазий, узнав о судьбе своей супруги, прибыл к ней для совместной жизни» (Amm. Marc. XIX. 9. 4). Несмотря на то, что для Краугазия такое решение означало, по сути, государственную измену, напоминание оказалось вполне эффективным, и он соглашается на покровительство персов, после чего женщина обращается к персидскому царю с просьбой «принять под свою власть и ее супруга» (Amm. Marc. XIX. 9. 5). Аммиан Марцеллин отзывается об этих действиях без осуждения, скорее с сочувствием, отмечая, как она «Горевала при мысли, что ей предстоит переселение $<\ldots>$ в чужой мир без супруга» (Amm. Marc. XIX. 9. 3. 4). Вероятной причиной такого лояльного отношения является святость супружеских уз, превозносимая историком и ценимая даже выше преданности государству [Дмитриев, 2015, с. 36]. Однако в этом случае играет роль и подлинно феминный характер поведения женщины.

Значительными влиятельными возможностями обладали женщины, непосредственно облеченные властью. Формой такого влияния можно считать покровительство. По свидетельству Аммиана Марцеллина, именно «справедливое покровительство» императрицы Евсевии «спасло Юлиана от преследований и доставило ему звание цезаря» (Amm. Marc. XXI. 6. 4). Отметив, что в противном случае «он бы погиб под натиском позорной клики льстецов» (Amm. Marc. XV. 2. 8), историк положительно оценивает заступничество Евсевии за Юлиана, причем в этом сюжете акцент смещен с собственно политического вмешательства на моральный аспект спасения жизни невиновного: Евсевия «сре- 
ди своих современниц выделялась <...> нравственными качествами и при своем высоком положении проявляла гуманность» (Amm. Marc. XXI. 6. 4). Такая высокая оценка действий императрицы имеет выраженный личный оттенок, поскольку речь идет о Юлиане, который сыграл важную роль в жизни самого Аммиана и с которым его связывали достаточно близкие отношения, сложившиеся во время совместных персидских походов. Именно в период правления Юлиана, представленного в тексте «Деяний» в качестве образцового императора, довольно успешно развивалась военная карьера будущего историка, а после его смерти продвижение Аммиана Марцеллина на этом поприще прекратилось [Уколова, 1992, с. 44]. Эта личная заинтересованность историка в оценке событий очевидна, поскольку в целом моральный облик Евсевии далек от совершенства.

Иллюстрацией к сомнительности ее поведения и нравственных качеств, с одной стороны, и реального влияния на политическую ситуацию, с другой стороны, является сюжет о приглашении в Рим жены цезаря Юлиана, Елены, сделанного «под видом сердечного к ней расположения». Позднеантичный автор утверждает, что, «будучи сама бесплодной всю свою жизнь, Евсевия коварством заставила ее выпить особое снадобье, чтобы каждый раз, как она забеременеет, у нее случался выкидыш» (Amm. Marc. XVI. 10. 18). Причины подобного поступка автор видит не только в личной зависти, но и в политической плоскости, поскольку Евсевия стремилась предотвратить появление у Юлиана наследника, которому он оставит престол (Amm. Marc. XVI. 10. 19). Данный пример иллюстрирует вышеупомянутую подвижность оценок высокопоставленных женщин и их влияния, поскольку подобное поведение Евсевии явно идет вразрез с гуманностью и нравственностью, которые ей приписывает Аммиан в других ситуациях.

\section{Заключение}

Таким образом, анализ представленных в «Res Gestae» Аммиана Марцеллина сюжетов, связанных с гендерным взаимодействием, позволил прийти к следующим выводам. Не считая женщин самостоятельными властными фигурами, историк тем не менее приводит достаточно примеров их способности влиять на мнения и поступки мужчин как позитивным, так и негативным образом. Согласно первой модели, женское поведение предполагало мягкость, сдержанность, обладало умиротворяющим эффектом и коррелировало с гендерным стереотипом, восходящим к классической традиции и в полной мере соответствующим мировоззрению «последнего римлянина». Активное маскулинное поведение женщины, навязывание ею своей воли мужчине, энергичные действия, как правило, соответствовали второй модели, выходили за рамки присущей женщине социальной роли и, поскольку чаще приводили к результату, не соответствующему моральным нормам, имели негативные коннотации.

В тексте нашего историка довольно широко представлен инструментарий такой неявной женской власти, который включал эмоциональные реакции, в том числе страстные семейные связи, покровительственный эффект, а также материальные ресурсы.

Оценки, данные Аммианом Марцеллином женскому влиянию, не всегда прямо зависят от особенностей гендерного поведения, они в большей степени соотносятся с морализаторской направленностью текста, а также связываются с его личными пристрастиями и конкретными ситуациями. Решающим фактором при формулировке оценочных суждений зачастую выступает близость автора с описываемыми им персонажами, на жизни и карьере которых отразились проявления женской власти. В соответствии с этим, апеллируя к женскому влиянию, Аммиан подчеркивает политическую волю и независимость как достоинства правителя, либо акцентирует внимание на слабости и податливости, проявляющихся в невозможности противостоять этому влиянию, как его негативных чертах. 


\section{Список литературы}

1. Аммиан Марцеллин. Римская история. 1994. Пер. Ю.А. Кулаковского, А.И. Сонни. Отв. ред. Л.Ю. Лукомский. СПб., Алетейя, 558.

2. Банников А.В., Шмидт Г.А. 2013. Miles quondam scriptor rerum: проблема достоверности сведений по военной истории у Аммиана Марцеллина. В: Вестник Санкт-Петербургского университета. Серия 2. История. 4: 90-98.

3. Гонтарь Ю.С. 2012. Андрогиния как современное направление развития гендерного исследования студентов факультета социально-культурной деятельности МГУКИ. В: Вестник Московского государственного университета культуры и искусств. 1 (45): 193-198.

4. Григорюк Т.В. 2009. Цезарь Галл в античной историографии. В: Научные ведомости Белгородского государственного университета. История, политология. 7 (62): 10-15.

5. Дилигенский Г.Г. 1961. Северная Африка в IV-V веках. М., изд-во АН ССCР, 348.

6. Дмитриев В.А. 2007. Аммиан Марцеллин в отечественной историографии. В: Вестник Псковского государственного университета. Серия: Социально-гуманитарные науки. 1: 32-42.

7. Дмитриев В.А. 2015. Женщины в «Деяниях» Аммиана Марцеллина: к вопросу о гендерных представлениях «последних римлян». В: Научные ведомости Белгородского государственного университета. История, политология. 13 (210). Вып. 35: 30-38.

8. Ермолова И.Е. 2017. Констанций II в «Res gestae» Аммиана Марцеллина. В: Индоевропейское языкознание и классическая филология. СПб., Наука, 243-250. Уфа, 194.

9. Ибатуллин Р.И. 2000. Аммиан Марцеллин: проблемы биографии в контексте эпохи.

10. Латинско-русский словарь: около 50000 слов. 1976. Отв. ред. И.Х. Дворецкий. М., Русский язык, 1096.

11. Пинчукова И.В. 2017. Гендерный подход в исторической науке. В: Известия Алтайского государственного университета. 4: 117-120.

12. Рубцова M.В. 2005. Репрезентация политической организации Римской империи IV в. в «Res gestae» Аммиана Марцеллина. Барнаул, 164.

13. Уколова В.И. 1992. Поздний Рим: пять портретов. М., Наука, 157.

14. Харченко Ю.В. 2006. «Res Gestae» Аммиана Марцеллина в зарубежной историографии. В: Вестник Воронежского государственного университета. Серия: история, политология, социология. 2: 206-208.

15. Шеховцова Е.Е. 2008. Женщина и власть в Римской империи: постановка проблемы в аспекте методологии. В: Известия Российского государственного педагогического университета им. А.И. Герцена. 67: 314-318.

16. Ammianus Marcellinus. 1978. «Res Gestae». Ed. W. Seyfart. Leipzig. In 4 T.

17. Arjava A. 1996. Women and Law in Late Antiquity. New York, Ed., 304.

18. Barnes T.D. 1998. Ammianus Marcellinus and the Representation of Historical Reality. Ithaca, Cornell Univ. press, 290.

19. Blockley R.C. 1975. Ammianus Marcellinus: A Study of His Historiography and Political Thought. Bruxelles, Latomus, 210.

20. Cooper K. 1992. Insinuations of Womanly Influence: An Aspect of the Christianization of the Roman Aristocracy. In: The Journal of Roman Studies, № 82: 150-164.

21. Karau L. 1971. Das Bild der Frauen in den «Res Gestae» des Ammianus Marcellinus. Berlin, 455. Press, 378 .

22. Kelly G. 2008. Ammianus Marcellinus: The Allusive Historian. Cambridge, University

23. Matthews J.F. 1989. The Roman Empire of Ammianus. Baltimore, The Johns Hopkins University press, 608.

24. Sabbah G. 1991. Présences féminines dans l'Histoire d'Ammien Marcellin. Les rôles politiques. In: Cognitio gestorum. The Historiographic Art of Ammianus Marcellinus. Amsterdam, 91-105.

25. Tougher S. 2000. Ammianus Marcellinus on the Empress Eusebia: A Split Personality? In: Greece \& Rome. Vol. 47. № 1: 94-101.

26. Wieber-Scariot A. 1991. Zwischen Polemik und Panegyrik. Frauen des Kaiserhauses und Herrscherinnen des Ostens in den «Res gestae» des Ammianus Marcellinus. Trier, 464. 


\section{References}

1. Ammian Marcellin. 1994. Rimskaya istoriya [The Roman History]. Per. Y.A. Kulakovskogo, A.I. Sonni. Otv. red. L.Y. Lukomskiy. St. Petersburg, Aleteya, 558 (in Russian).

2. Bannikov A.V., Shmidt G.A. 2013. Miles quondam scriptor rerum: problema dostovernosti svedenii po voennoi istorii u Ammiana Marcellina [Miles quondam scriptor rerum: the problem of the reliability of information on military history by Ammianus Marcellinus]. In: Vestnik SanktPeterburgskogo universiteta. Seriya 2. Istoriya. 4: 90-98 (in Russian).

3. Gontar Y.S. 2012. Androginiya kak sovremennoe napravlenie gendernogo issledovaniya studentov faculteta socialno-kulturnoi deyatelnosti MGUKI [Androgyny as a modern direction in the development of gender studies of students of the Faculty of Social and Cultural Activities of Moscow State University of Culture and Arts]. In: Vestnik Moskovskogo gosudarstvennogo universiteta kulturi i iskusstv. 1 (45): 193-198 (in Russian).

4. Grigoruk T.V. 2009. Cesar Gall v antichnoi istoriographii [Caesar Gallus in ancient historiography]. In: Nauchnie vedomosti Belgorodskogo gosudarstvennogo universiteta. 7 (62): 10-15 (in Russian).

5. Diligensky G.G. 1961. Severnaya Africa v IV-V vekah [North Africa in the IV-V centuries]. Moscow, izd-vo AN SSSR, 348 (in Russian).

6. Dmitriev V.A. 2007. Ammian Marcellin v otechestvennoi istoriografii. In: Vestnik Pskovskogo gosudarstvennogo universiteta. Seriya: Sotcialno-gumanitarnye nauki. 1: 32-42.

7. Dmitriev V.A. 2015. Zhenschini v «Deyaniyah» Ammiana Marcellina: k voprosu o gendernih predstavleniyah «poslednih rimlyan» [Women in the «Res Gestae» by Ammianus Marcellinus: on the issue of gender representations of the «last Romans»]. Nauchnie vedomosti Belgorodskogo gosudarstvennogo universiteta. 13 (210). Vyp. 35: 30-38 (in Russian).

8. Ermolova I.E. 2017. Constanci II v «Res gestae» Ammiana Marcellina [Constantius II in «Res gestae» by Ammianus Marcellinus]. Indoevropeiskoe yazikoznanie i classicheskaya filologiya. St. Petersburg, Nauka, 243-250 (in Russian).

9. Ibatullin R.I. 2000. Ammian Marcellin: problemi biographii v kontekste epokhi [Ammianus Marcellinus: problems of biography in the context of the era]. Ufa, 194 (in Russian).

10. Latinsko-russky slovar: okolo 50000 slov. 1976 [Latin-Russian dictionary: about 50000 words]. Otv. red. I.H. Dvoretsky. Moscow, Russky yazik, 1096 (in Russian).

11. Pinchukova I.V. 2017. Genderny podkhod v istoricheskoy nauke [Gender approach in Historical Science]. In: Izvestiya Altayskogo gosudarstvennogo universiteta. 4: 117-120 (in Russian).

12. Rubtsova M.V. 2005. Reprezentatsia politicheskoi organizatsii Rimskoy imperii IV v. $\mathrm{v}$ «Res gestae» Ammiana Marcellina [Representation of the political organization of the Roman Empire in the 4th century in the «Res gestae» by Ammianus Marcellinus]. Barnaul, 164 (in Russian).

13. Ukolova V.I. Pozdni Rim: pyat portretov [Late Rome: five portraits]. Moscow, Nauka, 157 (in Russian).

14. Kharchenko Yu.V. 2006. «Res Gestae» Ammiana Martcellina v zarubeznoi istoriografii [«Res gestae» by Ammianus Marcellinus in foreign historiography]. In: Vestnik Voronezskogo gosudarstvennogo universiteya. Seriya: istiriya, politologiya, sociologiya. 2: 206-208 (in Russian).

15. Shehovtsova E.E. 2008. Zhenschina i vlast v Rimskoy imperii: postanovka problemi v aspecte metodologii [Woman and power in the Roman Empire: formulation of the problem in the aspect of methodology]. Izvestia Rossiyskogo gosudarstvennogo pedagogicheskogo universiteta im. A.I. Gercena. 67: 314-318 (in Russian).

16. Ammianus Marcellinus. 1978. «Res Gestae». Ed. W. Seyfart. Leipzig. In 4 T.

17. Arjava A. 1996. Women and Law in Late Antiquity. New York, Ed., 304.

18. Barnes T.D. 1998. Ammianus Marcellinus and the Representation of Historical Reality. Ithaca, Cornell Univ. press, 1998, 290.

19. Blockley R.C. 1975. Ammianus Marcellinus: A Study of His Historiography and Political Thought. Bruxelles, Latomus, 210.

20. Cooper K. 1992. Insinuations of Womanly Influence: An Aspect of the Christianization of the Roman Aristocracy. In: The Journal of Roman Studies. 82: 150-164.

21. Karau L. 1971. Das Bild der Frauen in den «Res Gestae» des Ammianus Marcellinus. Berlin, 455 (in German).

22. Kelly G. 2008. Ammianus Marcellinus: The Allusive Historian. Cambridge University Press, 378. 
23. Matthews J.F. 1989. The Roman Empire of Ammianus. Baltimore, The John Hopkins University press, 608.

24. Sabbah G. 1991. Présences féminines dans l'Histoire d'Ammien Marcellin. Les rôles politiques. In: Cognitio gestorum. The Historiographic Art of Ammianus Marcellinus. Amsterdam, 91-105 (in French).

25. Tougher S. 2000. Ammianus Marcellinus on the Empress Eusebia: A Split Personality? In: Greece \& Rome. Vol. 47. 1: 94-101.

26. Wieber-Scariot A. 1991. Zwischen Polemik und Panegyrik. Frauen des Kaiserhauses und Herrscherinnen des Ostens in den «Res gestae» des Ammianus Marcellinus. Trier, 464 (in German).

\section{ИНФОРМАЦИЯ ОБ АВТОРАХ}

Анохина Елизавета Леонидовна, аспирант кафедры всеобщей истории Белгородского государственного национального исследовательского университета, г. Белгород, Россия

Семичева Елена Александровна, кандидат исторических наук, доцент кафедры всеобщей истории Белгородского государственного национального исследовательского университета, г. Белгород, Россия

\section{INFORMATION ABOUT THE AUTHORS}

Elizaveta V. Anokhina, post-graduate student of the Department of General History, Belgorod State National Research University, Belgorod, Russia

Elena A. Semicheva, candidate of Historical Sciences, Associate Professor of the Department of General History, Belgorod State National Research University, Belgorod, Russia 